\title{
Cloning and Characterization of a Chromosomal Class C $\beta$-Lactamase and Its Regulatory Gene in Laribacter hongkongensis
}

\author{
Susanna K. P. Lau, ${ }^{1}$ Pak-leung Ho, ${ }^{1}$ Maria W. S. Li, ${ }^{1}$ Hoi-wah Tsoi, ${ }^{1}$ Raymond W. H. Yung, ${ }^{2}$ \\ Patrick C. Y. Woo, ${ }^{1}$ and Kwok-yung Yuen ${ }^{1 *}$ \\ Department of Microbiology, The University of Hong Kong, Hong Kong, ${ }^{1}$ and Department of Microbiology, \\ Pamela Youde Nethersole Eastern Hospital, Hong Kong ${ }^{2}$
}

Received 14 July 2004/Returned for modification 3 October 2004/Accepted 6 January 2005

\begin{abstract}
Laribacter hongkongensis, a newly discovered bacterium recently shown to be associated with communityacquired gastroenteritis, is generally resistant to most $\beta$-lactams except the carbapenems. We describe the cloning and characterization of a novel chromosomal class $C \beta$-lactamase and its regulatory gene in $L$. hongkongensis. Two genes, $\operatorname{ampC}$ and $a m p R$, were cloned by inserting restriction fragments of genomic DNA from $L$. hongkongensis strain HLHK5 into pBK-CMV to give the recombinant plasmid pBK-LHK-5. The ampR and $a m p C$ genes and their promoters were divergently oriented, with the $a m p R$ gene immediately upstream of the $a m p C$ gene and an intercistronic Lys-R motif, typical of inducible ampC-ampR regulatory systems. The deduced amino acid sequence of the cloned AmpC $\beta$-lactamase (pI 8.1) contained consensus motifs characteristic of class $C \beta$-lactamases but had identities no greater than $46 \%$ to known class $C \beta$-lactamases. The kinetic properties of this AmpC were also compatible with those of a class $C \beta$-lactamase. PCR of 20 clinical isolates of $L$. hongkongensis, including HLHK5, showed the presence of both ampC and ampR genes in all isolates. Southern hybridization suggested that the ampC gene of HLHK5 was chromosomally encoded. Subcloning experiments showed that the expression of the ampC gene of HLHK5 was regulated by its ampR gene, which acts as a repressor. The $\beta$-lactamase characterized from strain HLHK5 was named LHK-5 (gene, $\left.b l a_{\text {LHK-5 }}\right)$ and represents the first example of AmpC $\beta$-lactamase in the $\beta$ subdivision of proteobacteria.
\end{abstract}

Laribacter hongkongensis is a facultative anaerobic, nonsporulating, gram-negative, seagull-shaped or spiral rod first isolated from the blood and empyema thoracis of a patient with alcoholic liver cirrhosis in Hong Kong (31). Subsequently, it was isolated from the stools of six patients with communityacquired diarrhea (29). By use of a newly developed selective medium, cefoperazone MacConkey agar, L. hongkongensis has recently been shown to be associated with community-acquired gastroenteritis $(14,30)$. The isolation of $L$. hongkongensis from patients with gastroenteritis correlated with a history of travel and the consumption of fish. Moreover, the bacterium has been found in the intestines of freshwater fish, which may be the source of human infections (30). L. hongkongensis may be a globally emerging pathogen, as the travel histories of patients suggested that it is present in at least four continents, including Asia, Europe, Africa, and Central America $(29,30)$.

$L$. hongkongensis is generally resistant to $\beta$-lactams, including broad-spectrum penicillins and cephalosporins, but is susceptible to carbapenems, amoxicillin-clavulanate, quinolones, and aminoglycosides $(14,29,30,31)$. Antibiotic treatment is usually not necessary in patients with Laribacter gastroenteritis. However, a quinolone and amoxicillin-clavulanate would be the antibiotic of choice in immunocompromised adults and children, respectively. Since the bacterium displays extensive resistance to $\beta$-lactams, cephalosporins, which are sometimes used to treat bacterial gastroenteritis, may not be useful (30).

\footnotetext{
* Corresponding author. Mailing address: Department of Microbiology, The University of Hong Kong, University Pathology Building, Queen Mary Hospital, Hong Kong. Phone: (852) 28554892. Fax: (852) 28551241. E-mail: hkumicro@hkucc.hku.hk.
}

At the moment, the mechanism of $\beta$-lactam resistance in $L$. hongkongensis has not been investigated. Here we report on the cloning and characterization of a novel class $C \beta$-lactamase gene from clinical isolates of $L$. hongkongensis.

\section{MATERIALS AND METHODS}

Bacterial strains and plasmids. The bacterial strains and plasmids used for cloning in this study are listed in Table 1. L. hongkongensis strain HKU1 was isolated from the blood culture and empyema pus of a patient with bacteremic empyema thoracis (31). The other 19 isolates of L. hongkongensis (strains HLHK2 to HLHK20) were recovered from the stools of patients with community-acquired gastroenteritis $(14,29,30)$. The identities of all L. hongkongensis isolates were confirmed phenotypically by standard conventional biochemical methods and genotypically by $16 \mathrm{~S}$ rRNA gene sequencing.

Susceptibility testing. Antibiotic powders with known potencies, including sulbactam (Pfizer Corporation, Hong Kong, China) and clavulanic acid (SmithKline Beecham, Hong Kong, China), were kindly provided by the manufacturers. All other antibiotics were purchased from Sigma (St. Louis, Mo.). The MICs of the $\beta$-lactam antibiotics were determined by the broth macrodilution method for nonfastidious, aerobic bacteria, according to NCCLS guidelines (21), with Mueller-Hinton broth (Becton Dickinson, Cockeysville, Md.) and an inoculum of $5 \times$ $10^{5} \mathrm{CFU}$ per $\mathrm{ml}$ with incubation at $35^{\circ} \mathrm{C}$ for $20 \mathrm{~h}$. The MICs of ampicillin and cefoperazone were determined alone and in combination with $2 \mu \mathrm{g}$ of clavulanic acid per $\mathrm{ml}$ or $4 \mu \mathrm{g}$ of sulbactam per $\mathrm{ml}$. Control strains Staphylococcus aureus ATCC 29213 and Escherichia coli ATCC 25922 were included with each run.

Cloning experiments and recombinant plasmids. A genomic DNA library was constructed as described in our previous publications $(26,28)$. Briefly, total genomic DNA of an L. hongkongensis strain, strain HLHK5, was extracted from $100 \mathrm{ml}$ of culture broth and was partially digested with Sau3A (Roche, Mannheim, Germany). The partial digests with fragments of 2 to $4 \mathrm{~kb}$ were then ligated to the BamHI site of the vector provided by the ZAP Express vector kit (Strategene, La Jolla, Calif.), and a phage expression library was constructed according to the instructions of the manufacturer. The library had at least 1 million independent phage plaques, with more than $95 \%$ containing inserts of an average size of $2.5 \mathrm{~kb}$, as checked by restriction enzyme digestion of 100 clones with SalI and $\mathrm{XbaI}$ (Roche). The DNA inserts of phage clones were excised with the ExAssist helper phage in XL1-Blue $\mathrm{MRF}^{\prime}$ cells (Strategene), which yielded the pBK- 
TABLE 1. Bacterial strains and plasmids used in this study

\begin{tabular}{|c|c|c|}
\hline Strain or plasmid & Relevant genotype or phenotype & Source or reference \\
\hline \multicolumn{3}{|l|}{ Strains } \\
\hline E. coli XLOLR & $\begin{array}{l}\Delta(\text { mcrA }) 183 \Delta(\text { mcrCB-hsdSMR-mrr }) 173 \text { endA1 thi-1 recA1 gyrA96 relA1 lac }\left[\mathrm{F}^{\prime}\right. \\
\left.\left.\quad \text { proAB lacl }{ }^{\mathrm{q}} Z \Delta M 15 \mathrm{Tn} 10\left(\mathrm{Tet}^{\mathrm{r}}\right)\right] \mathrm{Su}^{-} \text {(nonsuppressing }\right) \lambda^{\mathrm{r}} \text { (lambda resistant) }\end{array}$ & Stratagene \\
\hline E. coli $\mathrm{TOP} 10$ & $\begin{array}{l}\mathrm{F}^{-} \text {mcrA } \Delta(\text { mrr-hsd } \mathrm{RMS}-m c r \mathrm{BC}) \text { } \phi 80 l a c \mathrm{Z} \Delta \mathrm{M} 15 \text { slacX74 recA1 araD139 } \Delta(\text { ara- } \\
\text { leu }) 7697 \text { galU galK rpsL }\left(\mathrm{Str}^{\mathrm{r}}\right) \text { endA1 nupG }\end{array}$ & Invitrogen \\
\hline \multicolumn{3}{|l|}{ Plasmids } \\
\hline pBK-CMV phagemid & Cloning vector; neomycin and kanamycin resistant & Stratagene \\
\hline pACYC184 & Cloning vector; chloramphenicol and tetracycline resistant & NEB, Beverly, Mass. \\
\hline pBK-LHK-5 & $\begin{array}{l}\text { Recombinant plasmid containing a } 2.5-\mathrm{kb} \text { Sau3A-digested fragment from genomic } \\
\text { DNA of } L \text {. hongkongensis HLHK5 in pBK-CMV }\end{array}$ & This report \\
\hline pLHKC & $\begin{array}{l}\text { Recombinant plasmid containing } a m p C \text { gene of L. hongkongensis HLHK5 in } \\
\text { pACYC184 }\end{array}$ & This report \\
\hline pLHKCR & $\begin{array}{l}\text { Recombinant plasmid containing } a m p C \text { and } a m p R \text { genes of L. hongkongensis } \\
\text { HLHK5 in pACYC184 }\end{array}$ & This report \\
\hline
\end{tabular}

CMV phagemid vector. E. coli XLOLR cells were then infected with the pBK$\mathrm{CMV}$ phagemid, which yielded the pBK-CMV plasmid with the cloned inserts in E. coli XLOLR cells. Antibiotic-resistant clones were selected on Luria-Bertani (LB) plates containing $32 \mu \mathrm{g} / \mathrm{ml}$ cefoperazone and $50 \mu \mathrm{g} / \mathrm{ml}$ kanamycin. Recombinant plasmid DNA was prepared with a High Pure plasmid isolation kit (Roche) from 1-ml LB broth cultures incubated with $32 \mu \mathrm{g} / \mathrm{ml}$ cefoperazone and $50 \mu \mathrm{g} / \mathrm{ml}$ kanamycin overnight at $37^{\circ} \mathrm{C}$. The sizes of the inserted fragments were estimated according to the bacteriophage $\lambda$ AvaII digest DNA marker (MBI Fermentas).

DNA sequencing, PCR amplification, and sequence analysis. The primers used in this study are listed in Table 2. Cloned DNA fragments in pBK-CMV were sequenced with vector primers of pBK-CMV (T3 and T7) and synthetic primers (LPW606 and LPW608), designed from the sequencing data of the first round of the sequencing reaction. Bidirectional DNA sequencing was performed with an ABI automatic sequencer (Perkin-Elmer, Norwalk, Conn.), according to the instructions of the manufacturer (26). The DNA sequence was analyzed by a search with the BLAST program on the National Center for Biotechnology Information server at the National Library of Medicine (Bethesda, Md.; http: //www.ncbi.nlm.nih.gov). The searches were performed at both the protein and the DNA levels.

The genomic DNA of 20 clinical isolates of L. hongkongensis (isolates HKU1 and HLHK2 to HLHK20) was extracted as described previously (31). The prevalence of the cloned $\beta$-lactamase genes of $L$. hongkongensis was studied by PCR with laboratory-designed primers specific for the $a m p C$-coding region (primers LPW663 and LPW664) and the ampR-coding region (primers LPW621,
LPW622, LPW665, and LPW679). The PCR products of seven L. hongkongensis strains (strains HKU1 and HLHK2 to HLHK7) were also sequenced and analyzed by using additional sequencing primers specific for $\operatorname{ampC}$ genes (primers LPW608 and LPW697). The deduced protein sequences of $a m p C$ and $a m p R$ were compared with known sequences in the GenBank database by multiplesequence alignment with the CLUSTAL W program (25). The phylogenetic relationships of the $\operatorname{ampC}$ and $\operatorname{ampR}$ genes of L. hongkongensis to the corresponding related genes were determined with the Clustal X program (version 1.81) (11) and by the neighbor-joining method with GrowTree software (Genetics Computer Group, Inc., San Diego, Calif.).

Southern hybridization of $\boldsymbol{\beta}$-lactamase gene. DNA from $L$. hongkongensis strain HLHK5 was used for Southern hybridization analysis. Plasmid DNA was prepared with a High Pure plasmid isolation kit (Roche) and a Large Construct kit (QIAGEN, Hilden, Germany). The eluent was subjected to agarose gel electrophoresis and pulsed-field gel electrophoresis (PFGE), as described previously, with slight modifications (13). Agarose plugs containing total DNA and total DNA digested with SpeI were also prepared and subjected to PFGE. The restriction enzyme SpeI did not cut within the 298-bp $b l a_{\text {LHK-5 }}$ probe region prepared from the sequences obtained by PCR with primers LPW663 and LPW622 at an annealing temperature of $55^{\circ} \mathrm{C}$ targeted within the $\operatorname{ampC}$ gene. Southern blot hybridization with Hybond $\mathrm{N}^{+}$membranes (Amersham International, Little Chalfont, United Kingdom) was modified from our previously published protocol $(27,30)$. After hybridization with the digoxigenin-labeled probe (the denatured PCR product), the nylon membrane was washed twice with $2 \times \operatorname{SSC}(1 \times$ SSC is $0.15 \mathrm{M} \mathrm{NaCl}$ with $0.015 \mathrm{M}$ sodium citrate $)-0.1 \%$ sodium

TABLE 2. Primers used in this study

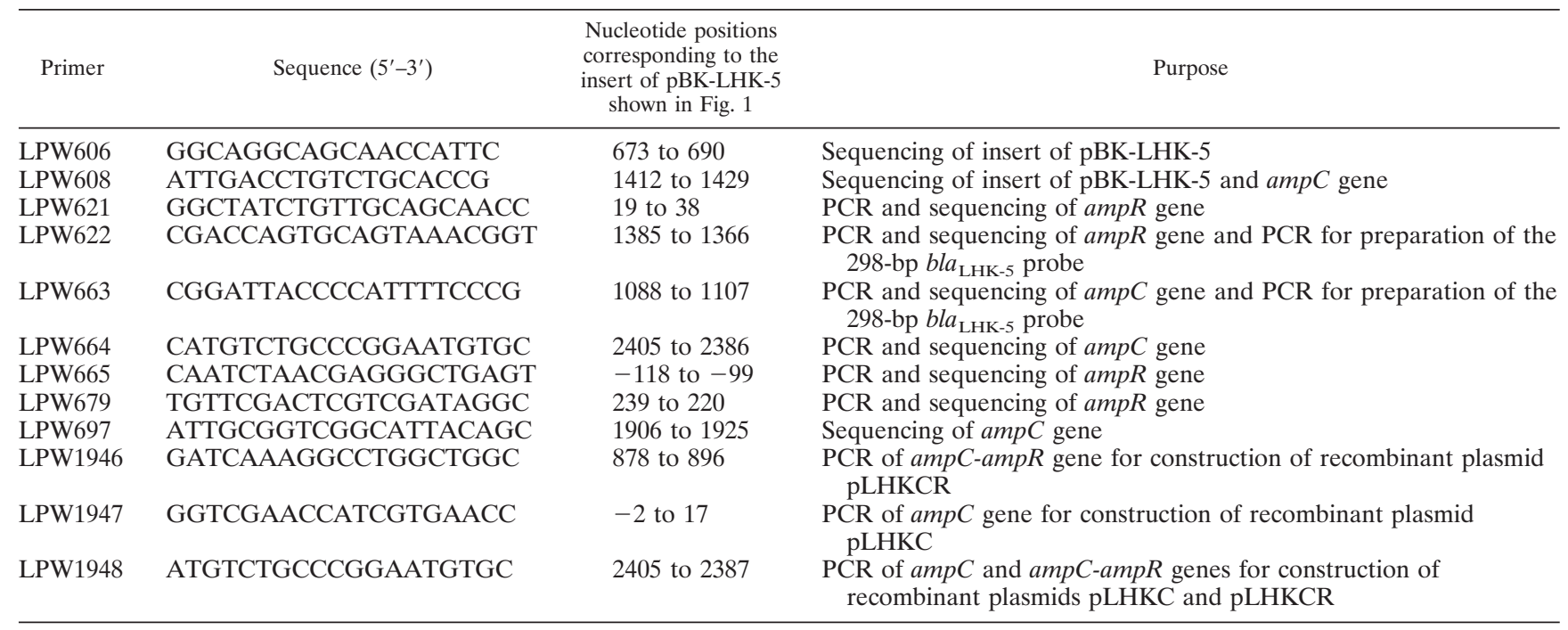


TABLE 3. MICs of $\beta$-lactams for seven clinical isolates of L. hongkongensis, E. coli XLOLR harboring recombinant plasmid pBK-LHK-5, and $E$. coli XLOLR

\begin{tabular}{|c|c|c|c|c|c|c|c|c|c|c|c|c|c|}
\hline \multirow{2}{*}{ Bacterial strain } & \multicolumn{13}{|c|}{$\operatorname{MIC}(\mu \mathrm{g} / \mathrm{ml})^{b}$} \\
\hline & AMP & AMP-CA & AMP-SBM & FOX & CXM & CAZ & CTX & $\mathrm{CPZ}$ & CPZ-SBM & FEP & ATM & IPM & MPM \\
\hline \multicolumn{14}{|l|}{ L. hongkongensis } \\
\hline HKU1 & 32 & 32 & 16 & 16 & 16 & $>256$ & 64 & $>256$ & $>256$ & 64 & $>256$ & 0.0625 & 0.0625 \\
\hline HLHK2 & 128 & 128 & 64 & 128 & 256 & $>256$ & $>256$ & $>256$ & $>256$ & $>256$ & $>256$ & 0.0625 & 0.0625 \\
\hline HLHK3 & 256 & 256 & 64 & 64 & 32 & $>256$ & 128 & $>256$ & $>256$ & 32 & $>256$ & 0.0625 & 0.03125 \\
\hline HLHK4 & 256 & 256 & 128 & 128 & 64 & $>256$ & 256 & $>256$ & $>256$ & $>256$ & $>256$ & 0.0625 & 0.0625 \\
\hline HLHK5 & 256 & 64 & 128 & 64 & 64 & $>256$ & 256 & $>256$ & $>256$ & 128 & $>256$ & 0.0625 & 0.0625 \\
\hline HLHK6 & 256 & 256 & 128 & 64 & 16 & 256 & 128 & $>256$ & $>256$ & 128 & $>256$ & 0.125 & 0.0625 \\
\hline HLHK7 & 64 & 64 & 64 & 64 & 32 & 128 & 128 & $>256$ & $>256$ & 2 & $>256$ & 0.0625 & 0.0625 \\
\hline \multicolumn{14}{|l|}{ E. coli } \\
\hline XLOLR(pBK-LHK-5) ${ }^{a}$ & 64 & 64 & 32 & 16 & 128 & 64 & 32 & $>256$ & $>256$ & 32 & $>256$ & 0.125 & 0.0625 \\
\hline XLOLR & 8 & 4 & 4 & 16 & 32 & 4 & 8 & 8 & 8 & 8 & 128 & 0.125 & 0.0625 \\
\hline
\end{tabular}

${ }^{a}$ This strain, which harbors the recombinant plasmid pBK-LHK-5, produced the LHK-5 $\beta$-lactamase.

${ }^{b}$ AMP, ampicillin; AMP-CA, ampicillin plus clavulanic acid $(2 \mu \mathrm{g} / \mathrm{ml})$; AMP-SBM, ampicillin plus sulbactam (4 $\left.\mu \mathrm{g} / \mathrm{ml}\right)$; FOX, cefoxitin; CXM, cefuroxime; CAZ, ceftazidime; CTX, cefotaxime; CPZ, cefoperazone; CPZ-SBM, cefoperazone plus sulbactam (4 $\mu \mathrm{g} / \mathrm{ml})$; FEP, cefepime; ATM, aztreonam; IPM, imipenem; MPM, meropenem.

dodecyl sulfate (SDS) at room temperature for $30 \mathrm{~min}$, followed by washing with $0.5 \times \mathrm{SSC}-0.1 \% \mathrm{SDS}$ at room temperature for $30 \mathrm{~min}$ and $0.1 \times \mathrm{SSC}-0.1 \%$ SDS at $55^{\circ} \mathrm{C}$ for $30 \mathrm{~min}$.

$\boldsymbol{\beta}$-Lactamase assays and IEF analysis. $\beta$-Lactamase from cultures of $E$. coli XLOLR harboring pBK-LHK-5 was extracted by sonication as described in our previous publications $(4,10)$. Isoelectric focusing (IEF) analysis of the $\beta$-lactamase was performed with an ampholine gel (Pharmacia, Hong Kong, China) from $\mathrm{pI} 3.5$ to $\mathrm{pI}$ 9.5. Enzyme extracts from strains expressing TEM-1 (pI 5.4), OXA-1 (pI 7.4), and SHV-1 (pI 7.6) were used as controls. The pI value of each enzyme was determined by overlaying the gel with nitrocefin (24). Substrate and inhibition assays were performed as described previously (4). The wavelengths were $235 \mathrm{~nm}$ for benzylpenicillin and cefoxitin; $255 \mathrm{~nm}$ for cephaloridine, cephalothin, and cefoperazone; $257 \mathrm{~nm}$ for ceftazidime and cefepime; and $297 \mathrm{~nm}$ for meropenem. The $V_{\max }$ and $K_{m}$ values were calculated by use of the LineweaverBurk plot with the built-in Enzymatic Mechanism software (3). All kinetic studies were performed in triplicate.

Regulation of ampC expression. Expression of ampC of L. hongkongensis was studied after it was cloned into a plasmid of relatively low copy number (20 to 30 copies), pACYC184. By using the DNA sequence of the cloned fragment of recombinant plasmid pBK-LHK-5 with L. hongkongensis HLHK5 as the template, primers LPW1946 and LPW1948 were used for amplification of the ampC and $a m p R$ genes and primers LPW1947 and LPW1948 were use for amplification of the $a m p C$ gene. The PCR products obtained were cloned into the BamHI site of pACYC184. The resulting recombinant plasmids, pLHKC and pLHKCR (Table 1), were transformed into E. coli TOP10, and both constructs were resequenced. The MICs for E. coli TOP10 harboring the full-length (pLHKCR) or $a m p R$ deletion (pLHKC) constructs with or without imipenem $(0.0625 \mu \mathrm{g} / \mathrm{ml})$ or cefoxitin $(8 \mu \mathrm{g} / \mathrm{ml})$ were determined (6). The disk approximation test was also performed by using disks of cefoxitin $(30 \mu \mathrm{g})$ or imipenem $(10 \mu \mathrm{g})$ placed against ampicillin $(10 \mu \mathrm{g})$, cephaloridine $(30 \mu \mathrm{g})$, ceftriaxone $(30 \mu \mathrm{g})$, and cefoperazone $(70 \mu \mathrm{g})$ disks on Mueller-Hinton agar plates inoculated with the $E$. coli clones, as described previously $(17,23)$. The plates were examined after overnight incubation at $37^{\circ} \mathrm{C}$.

Nucleotide sequence accession numbers. The nucleotide sequence data for the $b l a C_{\mathrm{LHK}}$ gene have been lodged within the GenBank sequence database under accession numbers AY632070 for bla $C_{\mathrm{LHK}-1}$, AY632071 for bla $C_{\mathrm{LHK}-2}$, AY632072 for $b_{l a} C_{\mathrm{LHK}-3}$, AY632073 for bla $C_{\mathrm{LHK}-4}$, AY632074 for bla $C_{\mathrm{LHK}-5}$, AY632075 for $b_{l a} C_{\text {LHK-6, }}$, and AY632076 for bla $C_{\text {LHK-7 }}$.

\section{RESULTS}

Antibiotic susceptibilities. The MICs of $\beta$-lactams for seven strains of L. hongkongensis (strain HKU1 and HLHK2 to HLHK7) showed that they were resistant to all $\beta$-lactams except imipenem and meropenem (Table 3). When LHK5 was expressed in E. coli XLOLR (pBK-LHK5), it conferred resis- tance to ampicillin, ampicillin-clavulanic acid, ampicillin-sulbactam, cefuroxime, ceftazidime, cefoperazone, and cefoperazone-sulbactam; but less resistance to cefotaxime and cefepime was evident.

Cloning and sequence analysis of $\boldsymbol{b l a}_{\mathrm{LHK}-5}$. Six identical recombinant $E$. coli XLOLR clones were obtained. One clone with an insert of 2,529 bp (pBK-LHK-5) was selected for further analysis. The insert contained two open reading frames (ORFs), one of 1,173 bp that encoded a 390-amino-acid sequence with identities of no greater than $46 \%$ to known class C $\beta$-lactamases and the other of 888 bp that encoded a 295 amino-acid sequence with identities of no greater than $65 \%$ to known $a m p R$ genes (Fig. 1). The two ORFs are divergently oriented with overlapping -35 and -10 promoter regions. A Lys-R motif (CAAAATCAATTCA) was also found inside the 190-bp ampC-ampR intercistronic region (Fig. 2) (8, 15). The deduced amino acid sequence of the $\operatorname{amp} C$ gene contained the consensus sites, SLSK, which is characteristic of serine $\beta$-lactamases (20), and YSN and KTG, which are characteristic of class $C \beta$-lactamases $(12,18)$. At amino acid positions 247 to 250 , where another structural element characteristic of class $C$ $\beta$-lactamases was expected, the amino acid residues DEET were found (Fig. 1) (22). The deduced amino acid sequence of the ampR gene contained a helix-turn-helix domain at the $\mathrm{N}$ terminus (Fig. 1) (8, 15).

Diversity and phylogenetic analysis of $\boldsymbol{b l a}_{\mathbf{L H K}}$. The deduced amino acid sequence of bla $C_{\mathrm{LHK}-5}$ had $46 \%$ amino acid identities with the AmpC sequences of Sinorhizobium meliloti (GenBank accession no. CAC49440) and Ralstonia metallidurans (GenBank accession no. ZP_00023977) and the $\beta$-lactamase of Pseudomonas aeruginosa (GēnBank accession no. AAM08945) (Fig. 3). The deduced amino acid sequence of the $a m p R$ gene of HLHK5 had $65 \%$ amino acid identities with those of Ochrobactrum anthropi (GenBank accession no. CAC04521) and P. aeruginosa PAO1 (GenBank accession no. AAG07496) and 63\% amino acid identity with that of Pseudomonas fluorescens PfO-1 (GenBank accession no. ZP_00087575) (Fig. 4). PCR of all 20 isolates of $L$. hongkongensis showed bands at about $1,300 \mathrm{bp}$ for the $a m p C$ gene and bands at about $1,350 \mathrm{bp}$ for the $a m p R$ gene. Sequencing 


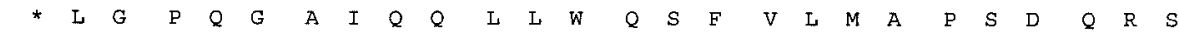

1 tcaaaggcet ggctggccgg ctatctgttg cagcaaccat tgactgaaga ccagcatgge cgggctatec tgcctggact 80

gcaatttgac cagccagtac tgtcctgtcg acaggccggg cgaaaaaggc tgtaccagtt caccecgcgc cagtgcgcgg 160

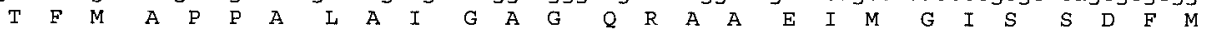

161 gtaacatcg ceggaggege cagtgcgata cctgcacect gecgggcgge tteaatcatg cetatcgacg agtcgaacat 240 $\begin{array}{lllllllllllllllllllllllll}I & S & N & R & I & F & V & P & H & G & V & G & A & E & R & L & W & Q & P & W & E & D & A & R & Y\end{array}$

241 gatgetgttc cggatgaaga ccggatggec taceceggec tetcgeagce attgeggeca ttcgtcagcg cggtatgage 320

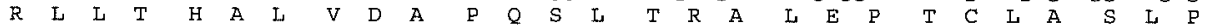

321 ggagcagggt atgggccagc acgtcggccg gttggetgag cgtcetcgec agttccggtg tgcaaagcge actgagcggt 400

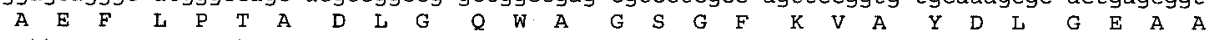

401 gettcgaaca geggegtgge atctaggece tgecacgetc cggagecgaa tttcactgeg taatccagec ectccgecge 480

$\begin{array}{llllllllllllllllllllllllllllll}I & D & V & R & N & N & H & T & S & L & R & L & D & I & R & P & H & S & N & V & F & G & P & L & R & P\end{array}$

481 aatgtccacc eggttgttgt gegtggacag gegcaggtca atccggggat ggctgtttac aaagceggge aggegcggca 560

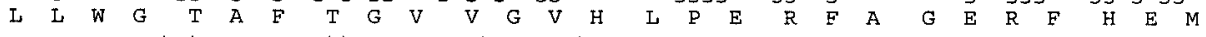

561 aagccagcc tgtggcaaaa gttccgacca ctcegacatg cagcggtteg egaajggcce cttcacggaa gtgetccatg 640 $\begin{array}{lllllllllllllllllllllllllllllllll}T & \text { L } & A & I & S & D & F & S & R & S & V & A & P & L & L & W & E & G & E & R & T & I & M & L & G & R & P\end{array}$

641 gtcagcgcaa tactgtcaaa cgaccggctg acggcaggca gcaaccattc gecttcgcgg gtaagcatca ggccgcgggg 720

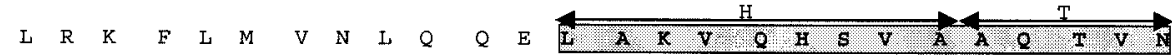

721 caaccgettg aacagcatga cattcagctg ctgctccagt gecttgacct gatgactgac ggcggcetgg gtaacgttca 800

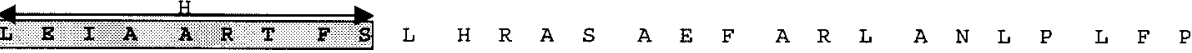

801 gctcaatagc cgcccgggta aagctcagat ggcgtgetga agcctcaaac gccegcaatg cattcaaagg tagaaatggt 880

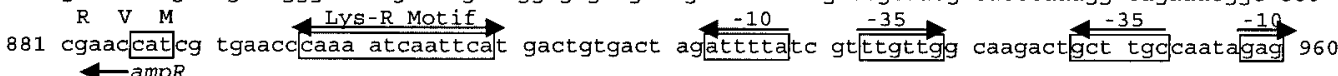
$\leftarrow$ ampR

961 tcagcatcca tetceggcac ggacaaaaca ggacatcatc atgttttgac tgccgggcac tgcaccttgc cgaacagcgg 1040 $a m p C \rightarrow$

1041 ctcaaatcga tcggcatatc catacggaac aaacaggcat gaaaaaacgg attaccccat tttcccgatt tgcatcaaaa 1120 $\begin{array}{llllllllllllllllll}M & K & K & R & I & T & P & F & S & R & F & A & S & K\end{array}$

1 K 10

1121 ggcctttccg cetgtagcge aggcatgttg etggtgacgg tggcacatge cgccaatacg gcagcagcge cagccggcat 1200

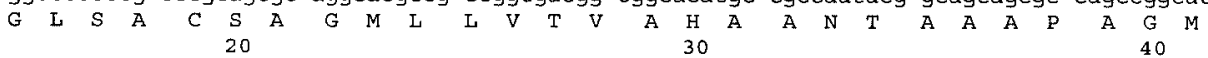

1201 ggatgccatg gtccaaaccg tgatgcaggc acaccagatt ccgggcatgg ccattgccat catccagcet ggcaagacca 1280

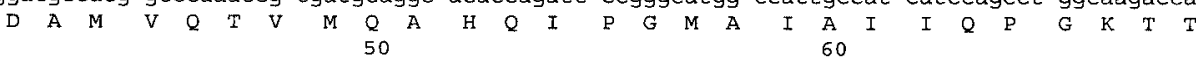

1281 ettatcacaa ttatggtgte gectccegeg aaaceggeca gecggtecgg gaaaccacce tgtttgaaat cggetccett 1360

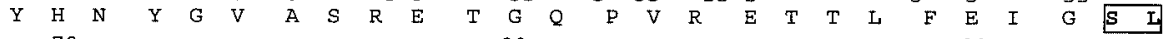
$70 \quad 80 \quad 90$

1361 tecaaacegt ttactgcact ggtcgcccag cgggctgaaa ccgaaggccg gattgacetg tetgcaccgg ccagccgeta 1440 \begin{tabular}{llllllllllllllllllllllllllllll}
\hline & $\mathbf{K}$ & $\mathrm{P}$ & $\mathrm{F}$ & $\mathrm{T}$ & $\mathrm{A}$ & $\mathrm{L}$ & $\mathrm{V}$ & $\mathrm{A}$ & $\mathrm{Q}$ & $\mathrm{R}$ & $\mathrm{A}$ & $\mathrm{E}$ & $\mathrm{T}$ & $\mathrm{E}$ & $\mathrm{G}$ & $\mathrm{R}$ & $\mathrm{I}$ & $\mathrm{D}$ & $\mathrm{L}$ & $\mathrm{S}$ & $\mathrm{A}$ & $\mathrm{P}$ & $\mathrm{A}$ & $\mathrm{S}$ & $\mathrm{R}$ & $\mathrm{Y}$
\end{tabular} $100 \quad 110 \quad 120$

1441 egttaccgec ctgeggggea gtgcattcga ccggatcace ctcaggcage teggtactta tagcgcagge ggattaccge 1520 $\begin{array}{lllllllllllllllllllllllllllllllllll}V & T & A & L & R & G & S & A & F & D & R & I & T & L & R & Q & L & G & T & Y & S & A & G & G & L & P & L\end{array}$ 130

1521 tccagtttec tgacaatgte accacccegg cagatgtget ggettattac cggcattgge aacctgtcca tecggcaggc 1600

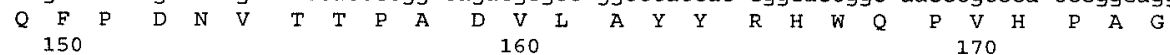

1601 accacccgge tgtattccaa tccgagcatt ggcctgatgg ggetggetge cagcctggea accggagagt cetttgecgg 1680

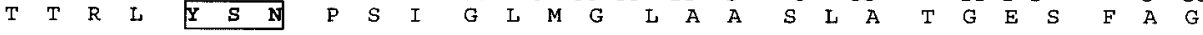
180 200

1681 cctgetcggg acaacggtge tgcaaccect eggcatgaac tegacetate tgcaagtgce eccggaggec egttcacgtt 1760 $\begin{array}{lllllllllllllllllllllllllll}L & L & G & T & T & V & L & Q & P & L & G & M & N & S & T & X & L & Q & V & P & P & E & A & R & S & R & Y\end{array}$ 210

1761 atgccatggg ttataccgec gecgggaaac cggtcagggt caaccceggt cegctggatg aggaaaccta cggcgtcaag 1840

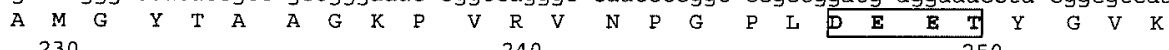

184 I tceacaaceg cagacatggt cggattttta ttggegcata tggaccetgc acgcagcaaa ggtgcattge ggteggcatt 1920

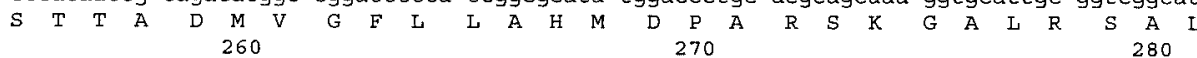

1921 acagcaaaca cgtgtaccgg tttattgcge cggacagace eggcaaggac tgggetggga aagttatcaa gactggaaaa 2000 $\begin{array}{llllllllllllllllllllllllllllllllll}Q & Q & T & R & V & P & V & Y & C & A & G & Q & T & R & Q & G & L & G & W & E & S & Y & Q & D & W & K & N\end{array}$ 290

2001 acctcgacat gctgetggeg ggaaattcaa atcaaatggt gtttgaaceg cagctggtaa aagectgtec tgccggcace 2080

$\begin{array}{llllllllllllllllllllllllllllllllll}L & D & M & L & L & A & G & N & S & N & Q & M & V & F & E & P & Q & L & V & K & A & C & P & A & G & T\end{array}$

310320

2081 atgaatgagc ceaatgtgtg ggtcaacaag accggttcta ctgcgggatt cggcgettat gecgtattcc tgcctgcceg 2160

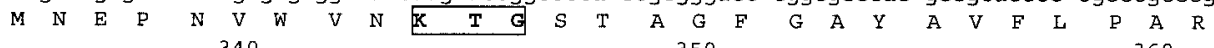
$340 \quad 350 \quad 360$

2161 acaaaccgge attgtcatcc tggccaaccg taattacceg attgcagacc gtatecgget egetcacgga attttgaceg 2240

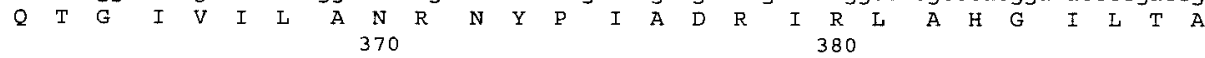

2241 cattgcactg a

L. $\mathrm{H} \star$

2251

FIG. 1. Nucleotide and deduced amino acid sequences of the insert of pBK-LHK-5 containing the ampC-and ampR-coding regions. The deduced amino acid sequences are designated in single-letter code. The putative promoter sequences, represented by -35 and -10 regions, and the Lys-R motif are boxed and indicated by arrows. The start codons are indicated by arrows, and the stop codons are underlined. The shaded areas represent the predicted helix-turn-helix motif of the LysR family. For AmpC, the consensus sites characteristic of serine $\beta$-lactamases or class C $\beta$-lactamases are in boldface and boxed. 

HLHK5
o. anthropi
P. aeruginosa
M. morganii
S. marcescens
C. freundii
H. alvei

Lys $R$ motif

-.............. CGTGAACDCAAAATCAATTCA-TGACTGTGACTAGATTTTATCG 43 - - - - - GTTGCCDCAAATT TTTCTAA-TGCCAAGTGCTAGATAACGTCG 42 .............. TCTCTGCTCCAAATTTTTCTAA-TGGCTGCCGCGAGTATTCGTCG 44 - - - - AATCCAC--CTGTAAGTTTTTCTTMAGGCTC-TTGTTATAATTAACCG 45 - - - TGTCGATAGCCA IAAGTTTTTCTITATGCTGGCTGAAATTATTA-TCG 47 - . . . . . . CATTAAGCCTCTTAGAAAAACTTA-TATCTGCTGCTAAATTTAACCG 46 AGGTCGCCTTAAGAAGTAGAGGCA TAAGATTTTCTTMAC-CCTAAGGGAATTTTATCTCG 59

TTTGTTGGCAAGACTGCTTGCCAATAGAGTCAGCATCCATCTCCGGCACGGACAAAACAG 103 TTTGTCGCG - - CC----AGCGCAAGCATTGTATATAAGCTGGGCCTGAAAGGCATATAT 95 TTTGCGGCAAATCC-.--TGCGCAAGCCTAG- - ATTTTCCCCGCCCGCCG-........ 88 TTTGTTCTG - - - TC- - - - TGGTGAATCTGACGATACTTGCCGCCGTCACTC--.--ACAC 93 CTTGTCAAC- - CC----GGCGGCAAAATCCGATATTTGGCGCGGCTGCT-------GTGA 94 TTTGTCAACACGG - - - - TGCAAATCAAAC- -ACACTGATTGC---GTCTGACGGGCCCG 96 CTTGTCAATCAGGC----GGCGATAGCGGAT-ATTCCTGCCGCTACGGTGAGCTTGGCGC 114
GACATCATCATGTTTTGACTGCCGGGCACTGCACCTTGCCGAACAGCGGCTCAAATCGAT 163 CCCGCAAAGCGGGCTTCAATATAATGGACCGCGCAATACCGGCTATGTCTTGAGAAAGAT 155 ACGGAAGGTTAATTCTG ... . . . . . . . . . . . . . . . . . . . 110 GCGTCGCCGCAGCCGTAAAGGAATGACATCATCAATCAGGGAAAGCGCCGTGCATAACGC 154 GACACCCTTTTGCTTTTAATTACGGA-ACTG-АTTTC-................. 131 GATG-ACGCCGATCTTTACTGGCTAATATAA-ACATTTTCTTTTGCATGCTGATTGGCGT 172

HLHK5
O. anthropi
P. aeruginosa
M. morganii
S. marcescens
C. Ereundii
H. alvei

CGGCATATCCATACGGAACAAACAGGC- $\ldots \ldots$

GCAGCGGAACGCATAATCATGAGGTTTATTTATCTGTC- $\ldots \ldots \ldots$

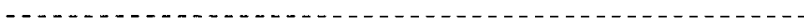

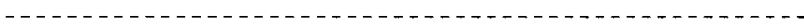

CAATAAAAACTTTTGGCCGCGGCCGATACCCTGCAACCTAAGAGCTTCTATC 206

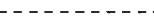

GCAAGACCCCAAATATATCCGATTAAAAGGTCACTTATTC_....... 212

FIG. 2. Multiple alignment of the DNA sequences of the ampC-ampR intercistronic regions of the $\beta$-lactamases of $L$. hongkongensis HLHK5, O. anthropi SLO74, P. aeruginosa PAO01, M. morganii GUI-1, Serratia marcescens, $C$. freundii OS60, and $H$. alvei HA-1. The Lys-R motif is boxed.

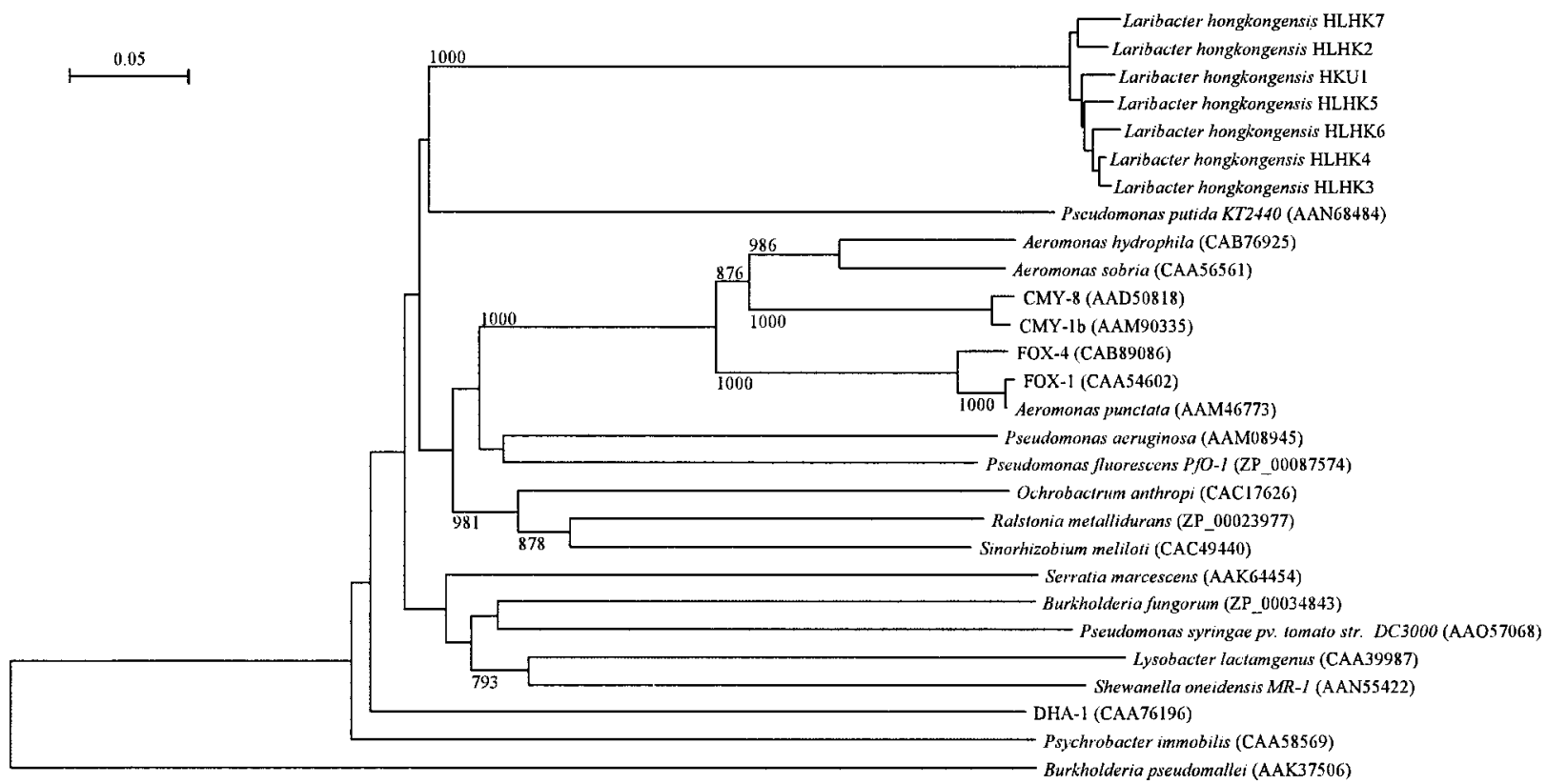

FIG. 3. Phylogenetic tree showing the relationships of the AmpC of L. hongkongensis to related chromosomally encoded or plasmid-encoded class $C \beta$-lactamases. The tree was constructed by using the neighbor-joining method and bootstrap values calculated from 1,000 trees. The scale bar indicates the estimated number of substitutions per 100 amino acids by use of the Jukes-Cantor correction. Names and accession numbers are given as cited in the GenBank database. 


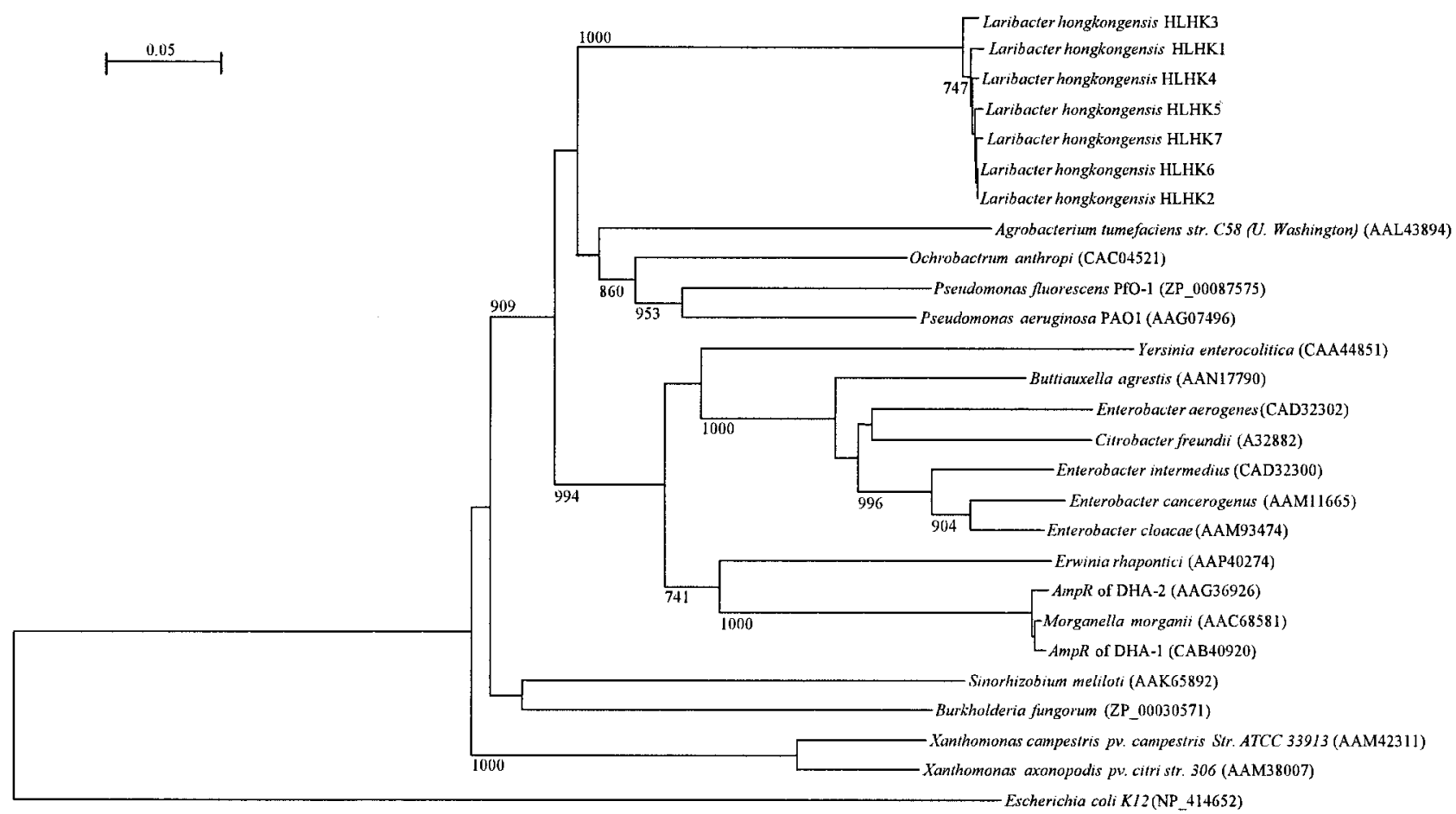

FIG. 4. Phylogenetic tree showing the relationships of the AmpR of L. hongkongensis to related AmpR proteins. The tree was constructed by using the neighbor-joining method and bootstrap values calculated from 1,000 trees. The scale bar indicates the estimated number of per 100 amino acids by use of the Jukes-Cantor correction. Names and accession numbers are given as cited in the GenBank database.

of the PCR products of HLHK5 showed that both genes were identical to those obtained from the E. coli XLOLR(pBKLHK-5) clone. Sequencing of the PCR products of the other six isolates (isolates HKU1, HLHK2 to HLHK4, HLHK6, and HLHK7) showed $95 \%$ to $97 \%$ amino acid identities of their AmpC sequences to that of HLHK5 (Fig. 3) and 98\% to 99\% amino acid identities of their AmpR sequences to that of HLHK5 (Fig. 4). The deduced amino acid sequences of the $a m p C$ genes were different among all seven isolates. The $a m p C$ genes of strains HKU1 and HLHK2 had six and three nucleotide deletions, respectively, resulting in two and one amino acid deletions at positions 38 to 39 and position 283, respectively. The deduced amino acid sequences of the $a m p R$ genes of strains HLHK2 and HLHK6 were identical.

Southern hybridization of $\boldsymbol{\beta}$-lactamase gene. Agarose gel electrophoresis and PFGE did not reveal the presence of a plasmid of $\leq 250 \mathrm{~kb}$ in L. hongkongenesis strain HLHK5 after plasmid extraction with the High Pure plasmid isolation kit (for plasmids of up to $50 \mathrm{~kb}$ ) and the Large Construct kit (for plasmids up to $250 \mathrm{~kb}$ ). However, PFGE of total DNA showed genomic DNA and an additional band at about $310 \mathrm{~kb}$ which may correspond to a potential plasmid. Genomic DNA, but not the additional band, hybridized with the $b l a_{\text {LHK- } 5}$-specific probe. A single band of about $150 \mathrm{~kb}$ from SpeI-digested total DNA also showed positive hybridization with the $b l a_{\mathrm{LHK}^{-5}}$ specific probe.

Biochemical properties and IEF analysis of LHK-5. IEF analysis of the $E$. coli XLOLR(pBK-LHK-5) clone revealed a $\beta$-lactamase with an isoelectric point of 8.1. The kinetic parameters of the $\beta$-lactamase enzyme are shown in Table 4.
Regulation of L. hongkongensis ampC expression. E. coli harboring the $a m p R$ deletion construct (pLHKC) showed higher MICs to ampicillin, cephaloridine, and cefoperzone $(128 \mu \mathrm{g} / \mathrm{ml},>256 \mu \mathrm{g} / \mathrm{ml}$ and $>256 \mu \mathrm{g} / \mathrm{ml}$, respectively) than $E$. coli harboring the full-length ampR-ampC (pLHKCR) con-

TABLE 4. Kinetic parameters of LHK-5 $\beta$-lactamase in E. coli XLOLR(pBK-LHK-5) ${ }^{a}$

\begin{tabular}{lcccc}
\hline Substrate or inhibitor & $\begin{array}{c}\text { Relative } \\
V_{\max }{ }^{b}\end{array}$ & $K_{m}(\mu \mathrm{M})$ & $\begin{array}{c}\text { Relative } \\
V_{\max } / K_{m}{ }^{b}\end{array}$ & $\mathrm{IC}_{50}(\mu \mathrm{M})^{c}$ \\
\hline Substrate & & & & \\
Benzylpenicillin & $2.8 \pm 0.35^{d}$ & $356 \pm 13$ & 0.7 & $\mathrm{NA}^{e}$ \\
Cephaloridine & $100 \pm 9$ & $88 \pm 10$ & 100 & NA \\
Cephalothin & $101 \pm 2$ & $56 \pm 2$ & 159 & NA \\
Cefoxitin & $<1$ & - & - & NA \\
Ceftazidime & $<1$ & - & - & NA \\
Cefepime & $1.05 \pm 0.09$ & - & - & NA \\
Cefoperazone & $<1$ & - & - & NA \\
Meropenem & $<1$ & - & - & NA \\
Inhibitor & & & & \\
Cloxacillin & NA & NA & NA & $0.0035 \pm 0.0$ \\
Clavulanate & NA & NA & NA & $138 \pm 2.1$ \\
Sulbactam & NA & NA & NA & $57 \pm 1.6$ \\
\hline
\end{tabular}

${ }^{a} E$. coli XLOLR haboring the recombinant plasmid pBK-LHK-5.

${ }^{b}$ Relative to that of cephaloridine, which was taken as $100 \%$.

${ }^{c} \mathrm{IC}_{50}$, concentration of $\beta$-lactamase inhibitor that inhibits $50 \%$ of the activity after $10 \mathrm{~min}$ of incubation at $37^{\circ} \mathrm{C}$. Cephaloridine $(50 \%$ inhibitory concentration, $150 \mu \mathrm{M})$ was used as the substrate.

${ }^{d}$ Data shown are the means \pm standard deviations of three measurements.

${ }^{e} \mathrm{NA}$, not applicable.

${ }^{f}$ - , in these cases, the hydrolysis parameters could not be determined ( $V_{\max }$ was too low or $K_{m}$ was too high). 
struct ( $16 \mu \mathrm{g} / \mathrm{ml}, 32 \mu \mathrm{g} / \mathrm{ml}$, and $1 \mu \mathrm{g} / \mathrm{ml}$, respectively), indicating that the expression of the L. hongkongensis ampC gene is negatively regulated by $a m p R$. However, no increase in the MICs to ampicillin or cefoperazone was observed in the presence of cefoxitin or imipenem. Similarly, no flattening of the ampicillin, cephaloridine, ceftriaxone, and cefoperazone zones of inhibition was observed on a lawn of E. coli expressing pLHKCR.

\section{DISCUSSION}

In this study, we identified a $\beta$-lactamase from a clinical isolate of L. hongkongensis and showed that the gene was also present in all other strains tested. Unlike most members of the family Enterobacteriaceae with an inducible chromosomal ampC gene, which are usually not resistant to ceftazidime or cefotaxime, unless the $a m p C$ gene is expressed at very high levels, L. hongkongensis is generally resistant to most $\beta$-lactams except the carbapenems, as in the case in O. anthropi (20). $\beta$-Lactamase inhibitors, clavulanic acid and sulbactam, did not restore its susceptibility to $\beta$-lactams. Expression of the $\beta$-lactamase of L. hongkongensis, LHK-5, in E. coli showed that the recombinant clone also displayed resistance to all $\beta$-lactams except cefoxitin and carbapenems. Therefore, the present $\beta$-lactamase, which is only distantly related to other class $\mathrm{C}$ $\beta$-lactamases, behaves differently if it is responsible for all the $\beta$-lactam resistance profiles in L. hongkongensis. However, whether the unusual aztreonam resistance in L. hongkongensis can be explained by the presence of this $\beta$-lactamase remains to be determined, as the E. coli XLOLR strain used in the present study is also intrinsically resistant to aztreonam. Moreover, the variability of the cefepime MICs of the different strains of L. hongkongensis suggests that the present AmpC may not be responsible for the cefepime resistance observed in some strains of $L$. hongkongensis. Further investigations should be carried out to determine if additional resistance mechanisms are responsible for the $\beta$-lactam resistance in $L$. hongkongensis.

Sequence analysis showed that the insert of the recombinant plasmid contains an $a m p C$ gene and an $\operatorname{ampR}$ gene. The two genes and their corresponding putative promoters were in opposite orientations, with the $a m p R$ gene immediately upstream of the $a m p C$ gene and an intercistronic region containing a Lys-R motif. Such an arrangement is typical of inducible $a m p C$ - $a m p R$ regulatory systems found in many other gramnegative bacteria, including Morganella and Citrobacter (15, 22 ). The sequences of both genes from the E. coli XLOLR(pBK-LHK-5) clone were identical to those obtained from the parental strain, HLHK5. Both genes were present in all the 20 strains tested. Sequence analysis of the $\operatorname{ampC}$ genes of seven strains of L. hongkongensis showed 3\% to $5 \%$ amino acid differences among their ampC gene sequences. Hybridization experiments suggested that the ampC gene in L. hongkongensis was probably chromosomally encoded and was present in the $150-\mathrm{kb}$ fragment of SpeI-digested total DNA. The result is consistent with the presence of $a m p C$ genes in all 20 strains of L. hongkongensis as determined by PCR, despite the absence of plasmids in some strains (unpublished data). The intercistronic region is long (190 bp), and the DNA sequence of this Lys-R motif in L. hongkongensis is more similar to those of $O$. anthropi (20) and P. aeruginosa (16) than to those of members of the family Enterobacteriaceae (Fig. 2). The 38-bp specific AmpR binding sites which have been outlined for the AmpR protein of Citrobacter freundii was not found, probably because the AmpR of L. hongkongensis is only distantly related to that of $C$. freundii (15) (Fig. 4).

The AmpC of L. hongkongensis represents a new class $\mathrm{C}$ $\beta$-lactamase, with less than $50 \%$ amino acid sequence homology to known class $C \beta$-lactamases. From phylogenetic analysis, it is only distantly related to other chromosomally encoded or plasmid-encoded class C $\beta$-lactamases (Fig. 3), with the highest amino acid sequence similarity $(46 \%)$ to the putative $\beta$-lactamase in the $1,683-\mathrm{kb}$ pSymB megaplasmid of the symbiotic bacterium $S$. meliloti (5). Nevertheless, it possessed properties characteristic of class $C \beta$-lactamases. The present ampC gene contained amino acid residues characteristic of serine $\beta$-lactamases (SXXK) and class $\mathrm{C} \beta$-lactamases (YXN and $\mathrm{KXG})(12,18,20)$. The kinetic parameters of LHK-5 revealed that the enzyme had strong activities against cephalothin and cephaloridine. Similar to other class $C \beta$-lactamases, such as those from $O$. anthropi (20) and Morganella morganii (22), the present enzyme only poorly hydrolyzed ceftazidime, cefoperazone, and cefoxitin. However, unlike LHK-5, other class $\mathrm{C}$ enzymes, when they are cloned into $E$. coli, usually confer cefoxitin resistance. Therefore, LHK-5 possesses properties more similar to those of the class C enzyme of Hafnia alvei, which neither hydrolyzes nor provides resistance to cefoxitin (6). The hydrolytic activity of LHK-5 was strongly inhibited by low concentrations of cloxacillin but was poorly inhibited by clavulanic acid and sulbactam.

The ampR of L. hongkongensis regulates the expression of $a m p C$ by acting as a repressor. However, induction of $a m p C$ by cefoxitin or imipenem was not observed in the present study. The reason for the lack of induction in L. hongkongensis remains to be determined. Although the inducible effects of cefoxitin or imipenem have been observed in the ampC-ampR systems of many gram-negative bacteria, a previous study with $O$. anthropi also failed to demonstrate such effects, and the authors attributed this to the high level of resistance to extended-spectrum cephalosporins conferred by the E. coli clone (20). It has been shown that the inducibility of ampC-ampR systems may depend on the availability of other elements, such as AmpD, AmpE, and AmpG (2). Further studies are required to determine whether the $a m p C-a m p R$ of L. hongkongensis exhibits a different regulatory profile or whether its induction effect can be demonstrated in other host systems with compatible accessory elements.

The present study represents the first report of an ampC gene and the $a m p C$-ampR system in the $\beta$ subdivision of the proteobacteria. While ampC-ampR systems have been almost exclusively reported in the $\gamma$ subdivision of proteobacteria, it has also been recently reported in the $\alpha$ subdivision $(9,20)$. $L$. hongkongensis is a member of the family Neisseriaceae under the $\beta$ subdivision of proteobacteria, in which the ampC gene has not previously been found (MEDLINE search up to June 2004). The presence of $a m p C$ genes in three subdivisions of proteobacteria suggests that $a m p C$ genes are ancient genes that may have been present before the divergence of these subdivisions or horizontally transferred between bacteria from different subdivisions. Nevertheless, its presence in a huge di- 
versity of bacteria, including both animal pathogens and environmental bacteria, implies that the gene has been maintained even in the absence of selective pressure from clinical antibiotic usage $(1,9)$. Although it has been proposed that the gene may be involved in peptidoglycan metabolism $(7,19)$, the exact function of $a m p C$ remains to be determined.

\section{ACKNOWLEDGMENTS}

This work was partly supported by the University Development Fund, University Research Grant Council, The University of Hong Kong, and the Research Fund for the Control of Infectious Diseases of the Health, Welfare and Food Bureau of the Hong Kong SAR Government.

\section{REFERENCES}

1. Barlow, M., and B. G. Hall. 2002. Origin and evolution of the AmpC $\beta$-lactamases of Citrobacter freundii. Antimicrob. Agents Chemother. 46:11901198.

2. Bennett, P. M., and I. Chopra. 1993. Molecular basis of $\beta$-lactamase induction in bacteria. Antimicrob. Agents Chemother. 37:153-158.

3. Bush, K., and R. B. Sykes. 1986. Methodology for the study of $\beta$-lactamases. Antimicrob. Agents Chemother. 30:6-10.

4. Cheung, T. K., P. L. Ho, P. C. Woo, K. Y. Yuen, and P. Y. Chau. 2002 Cloning and expression of class A $\beta$-lactamase gene blaA (BPS) in Burkholderia pseudomallei. Antimicrob. Agents Chemother. 46:1132-1135.

5. Finan, T. M., S. Weidner, K. Wong, J. Buhrmester, P. Chain, F. J. Vorholter, I. Hernandez-Lucas, A. Becker, A. Cowie, J. Gouzy, B. Golding, and A. Puhler. 2001. The complete sequence of the 1,683-kb pSymB megaplasmid from the N2-fixing endosymbiont Sinorhizobium meliloti. Proc. Natl. Acad. Sci. USA 98:9889-9894.

6. Girlich, D., T. Naas, S. Bellais, L. Poirel, A. Karim, and P. Nordmann. 2000 Biochemical-genetic characterization and regulation of expression of an ACC-1-like chromosome-borne cephalosporinase from Hafnia alvei. Antimicrob. Agents Chemother. 44:1470-1478.

7. Henderson, T. A., K. D. Young, S. A. Denome, and P. K. Elf. 1997. AmpC and $\mathrm{AmpH}$, proteins related to the class $\mathrm{C} \beta$-lactamases, bind penicillin and contribute to the normal morphology of Escherichia coli. J. Bacteriol. 179: 6112-6121.

8. Henikoff, S., G. W. Haughn, J. M. Calvo, and J. C. Wallace. 1988. A large family of bacterial activator proteins. Proc. Natl. Acad. Sci. USA 85:66026606.

9. Higgins, C. S., M. B. Avison, L. Jamieson, A. M. Simm, P. M. Bennett, and T. R. Walsh. 2001. Characterization, cloning and sequence analysis of the inducible Ochrobactrum anthropi AmpC $\beta$-lactamase. J. Antimicrob. Chemother. 47:745-754.

10. Ho, P. L., T. K. Cheung, W. C. Yam, and K. Y. Yuen. 2002. Characterization of a laboratory-generated variant of BPS $\beta$-lactamase from Burkholderia pseudomallei that hydrolyses ceftazidime. J. Antimicrob. Chemother. 50:723726.

11. Jeanmougin, F., J. D. Thompson, M. Gouy, D. G. Higgins, and T. J. Gibson. 1998. Multiple sequence alignment with ClustalX. Trends Biochem. Sci. 10:403-405.

12. Joris, B., J. M. Ghuysen, G. Dive, A. Renard, O. Dideberg, P. Charlier, J. M. Frere, J. A. Kelly, J. C. Boyington, P. C. Moews, and J. R. Knox. 1988. The active-site-serine penicillin-recognizing enzymes as members of the Streptomyces R61 DD-peptidase family. Eur. J. Biochem. 250:313-324.

13. Lau, S. K. P., P. C. Y. Woo, H. Tse, K. W. Leung, S. S. Y. Wong, and K. Y. Yuen. 2003. Invasive Streptococcus iniae infections outside North America. J. Clin. Microbiol. 41:1004-1009.
14. Lau, S. K. P., P. C. Y. Woo, W. T. Hui, M. W. S. Li, J. L. L. Teng, T. L. Que, W. K. Luk, R. W. M. Lai, R. W. H. Yung, and K. Y. Yuen. 2003. Cefoperazone MacConkey agar for selective isolation of Laribacter hongkongensis. J. Clin. Microbiol. 41:4839-4841.

15. Lindberg, F., L. Westman, and S. Normark. 1987. Regulatory components in Citrobacter freundii ampC $\beta$-lactamase induction. Proc. Natl. Acad. Sci. USA 82:4620-4624.

16. Lodge, J. M., S. D. Minchin, L. J. Piddock, and J. W. Busby. 1990. Cloning, sequencing and analysis of the structural gene and regulatory region of the Pseudomonas aeruginosa chromosomal ampC $\beta$-lactamase. Biochem. J. 272: 627-631.

17. Mahlen, S. D., S. S. Morrow, B. Abdalhamid, and N. D. Hanson. 2003. Analyses of ampC gene expression in Serratia marcescens reveal new regulatory properties. J. Antimicrob. Chemother. 51:791-802.

18. Matsumura, N., S. Minami, and S. Mitsuhashi. 1998. Sequences of homologous $\beta$-lactamases from clinical isolates of Serratia marcescens with different substrate specificities. Antimicrob. Agents Chemother. 42:176-179.

19. Morosini, M. I., J. A. Ayala, F. Baquero, J. L. Martinez, and J. Blazquez. 2000. Biological cost of AmpC production for Salmonella enterica serotype Typhimurium. Antimicrob. Agents Chemother. 44:3137-3143.

20. Nadjar, D., R. Labia, C. Cerceau, C. Bizet, A. Philippon, and G. Arlet. 2001 Molecular characterization of chromosomal class C $\beta$-lactamase and its regulatory gene in Ochrobactrum anthropi. Antimicrob. Agents Chemother. 45:2324-2330

21. National Committee for Clinical Laboratory Standards. 2003. Methods for dilution antimicrobial susceptibility tests for bacteria that grow aerobically. Approved standard M7-A6, 6th ed. National Committee for Clinical Laboratory Standards, Wayne, Pa.

22. Poirel, L., M. Guibert, D. Girlich, T. Naas, and P. Nordmann. 1999. Cloning, sequence analyses, expression, and distribution of ampC-ampR from Morganella morganii clinical isolates. Antimicrob. Agents Chemother. 43:769776 .

23. Sanders, C. C., and W. E. Sanders, Jr. 1979. Emergence of resistance to cefamandole: possible role of cefoxitin-inducible $\beta$-lactamases. Antimicrob. Agents Chemother. 15:792-797.

24. Siu, L. K., J. Y. Lo, K. Y. Yuen, P. Y. Chau, M. H. Ng, and P. L. Ho. 2000. $\beta$-Lactamases in Shigella flexneri isolates from Hong Kong and Shanghai and a novel OXA-1-like $\beta$-lactamase, OXA-30. Antimicrob. Agents Chemother. 44:2034-2038.

25. Thompson, J. D., D. G. Higgins, and T. J. Gibson. 1994. CLUSTAL W: improving the sensitivity of progressive multiple sequence alignment through sequence weighting, position-specific gap penalties and weight matrix choice. Nucleic Acids Res. 22:4673-4680.

26. Woo, P. C., P. K. Leung, H. W. Tsoi, and K. Y. Yuen. 2001. Cloning and characterisation of malE in Burkholderia pseudomallei. J. Med. Microbiol. 50:330-338.

27. Woo, P. C., P. K. Leung, H. W. Tsoi, B. Y. Chan, T. L. Que, and K. Y. Yuen. 2002. Characterization of a novel insertion sequence, ISBp1, in Burkholderia pseudomallei. Arch. Microbiol. 177:267-273.

28. Woo, P. C., P. K. Leung, S. S. Wong, P. L. Ho, and K. Y. Yuen. 2001. groEL encodes a highly antigenic protein in Burkholderia pseudomallei. Clin. Diagn. Lab. Immunol. 8:832-836.

29. Woo, P. C. Y., P. Kuhnert, A. P. Burnens, J. L. L. Teng, S. K. P. Lau, T. L. Que, H. H. Yau, and K. Y. Yuen. 2003. Laribacter hongkongensis: a potential cause of infectious diarrhea. Diagn. Microbiol. Infect. Dis. 47:551-556.

30. Woo, P. C. Y., S. K. P. Lau, J. L. L. Teng, T. L. Que, R. W. H. Yung, W. K. Luk, R. W. M. Lai, W. T. Hui, S. S. Y. Wong, H. H. Yau, and K. Y. Yuen. 2004. Association of Laribacter hongkongensis in community-acquired human gastroenteritis with travel and with eating fish: a multicentre case-control study. Lancet 363:1941-1947.

31. Yuen, K. Y., P. C. Y. Woo, J. L. L. Teng, K. W. Leung, M. K. Wong, and S. K. P. Lau. 2001. Laribacter hongkongensis gen. nov., sp. nov., a novel gram-negative bacterium isolated from a cirrhotic patient with bacteremia and empyema. J. Clin. Microbiol. 39:4227-4232. 